\title{
Venous Thromboembolism (VTE) and Assisted Reproductive Technologies (ART): A Complex Relationship
}

Strina I, Alviggi C, Rosa PD*, Avino L, Amoroso R, Marrone V, Mascia M, Cioffi G and Placido GD

Department of Neuroscience, Reproductive Science and Odontostomatology, University of Naples Federico II, Naples, Italy

\begin{abstract}
Assisted reproductive technologies (ART) seem to have a double way clinical association with hypercoagulation and possible thrombotic complications: venous thromboembolism (VTE) seems to be not frequent complications in women that perform ART but its incidence seem to be increased if compared to that related to spontaneous pregnancy. Several mechanisms support this clinical association such as pharmacological ovarian stimulation and its induced acquired thrombophilia, possible presence of inherited thrombophilia that represents a risk to develop VTE per se and the occurring of pregnancy with its spontaneous hypercoagulable state.
\end{abstract}

Yet in the daily clinical management the frequent use of antithrombotic drugs as aspirin and low molecular weight heparin to increase the rate of pregnancy after ART procedure may be a confounding factor to support this aspects in this clinical settings.

\section{Background}

Assisted reproductive technologies (ART) are associated to an increased risk to develop venous thromboembolism (VTE) compared to spontaneous pregnancy. Previous studies have found that VTE after a spontaneous conception is slightly more than 1 of 1000 pregnant women $[1,2]$, while in women undergoing ART it may raise of threefour fold increase [3]. The pathophysiological mechanism by this increase is related to medical ovarian stimulation, a pharmacological ovarian stimulation that increases the number of oocytes available for ART associated to the presence of other risk factors as thrombophilia. Pharmacological ovarian hyperstimulation, in fact is able to increase procoagulant status [4] of all women that may lead to thrombosis, as showed by several studies. However, available data about the magnitude and the duration of VTE risk in pregnancy after ART are conflicting just as data about the risk to develop VTE for all women that perform ART and not only for those that show pregnancy after ART.

Available data in the Literature are mainly reported by clinical reports as case reports or short clinical series, but a clear incidence of VTE for women that perform ART with or without a following successful pregnancy is difficult to be understood. A better understanding of this conflicting point could be helpful in future in order to increase knowledge of the VTE risk for women that perform ART.

Moreover, the potential different role of such drugs and their dosages to induce ovarian stimulation, the role of thrombophilia and the role of antithrombotic drugs to prevent VTE in this clinical setting should be better evaluated.

\section{Clinical Evaluation of Thrombophilia in Women ongoing ART}

Although the increasing of knowledge the successful rate of ART remains low. One of suggested cause of this low successful rate is the suboptimal vascular uterine perfusion during ART [5]. For this reason in these years some physician gave an increased attention to thrombophilic state and to the possible sub-optimal uterine perfusion induced by thrombophilia in these patients $[5,6]$. This critical point has also been suggested by several Authors concerning the increased number of patients carrying thrombophilia that show repeated ART failure [7]. A recent case control study confirms in fact that such thrombophilia is associated to recurrent ART failure [8,9]. Yet, in other studies the increased rate of thrombophilia and its statistical significance did not appear but probably different inclusion and exclusion criteria to select patients in these studies may have influenced results [1012]. However, the suggested suboptimal uterine perfusion and the potential role of thrombophilia may influence the current choice of physicians to add antithrombotic drugs to the regular treatment of women ongoing ART, in particular if they show previous ART-failures in their anamnesis. Aspirin and/or low molecular weight heparin in fact are frequently present as additional drugs in women ongoing ART after repeated ART failures [13-17]. This clinical and pharmacological approach may be frequently found in the daily clinical management of these patients and clear data on the improvement of ART procedures with antithrombotic drugs is still matter of discussion. A review from Dentali et al. [18] underlined as the use of LMWH is associated with increased pregnancy rate in several studies, as previously already reported, but following studies did not confirm this protective role of LMWH $[18,19]$. However, several studies and reviews did not show a protective role of aspirin for women ongoing ART and their main outcomes as increased pregnancy rate [20].

Probably a registry or double blind randomized trial with definite outcomes as pregnancy rate, increased live-birth rate, incidence of VTE that will include all possible variables from a clinical point of view, as associated antithrombotic treatment with LMWH or aspirin or LMWH plus aspirin may be helpful to clarify this intriguing issue.

\section{Clinical Evaluation of VTE Risk for Women ongoing ART}

Venous thromboembolism is a rare complication of management

${ }^{*}$ Corresponding author: Rosa PD, Department of Neuroscience, Reproductive Science and Odontostomatology, University of Naples Federico II, Naples, Italy, Tel: 00393398078146; E-mail: derosap85@gmail.com

Received December 26, 2017; Accepted January 10, 2018; Published January 14,2018

Citation: Strina I, Alviggi C, Rosa PD, Avino L, Amoroso R, et al. (2018) Venous Thromboembolism (VTE) and Assisted Reproductive Technologies (ART): A Complex Relationship. J Blood Lymph 8: 199. doi:10.4172/2165-7831.1000199

Copyright: (c) 2018 Strina l, et al. This is an open-access article distributed unde the terms of the Creative Commons Attribution License, which permits unrestricted use, distribution, and reproduction in any medium, provided the original author and source are credited. 
of ART [20] and its real incidence is really difficult to be understood for several reasons. The main trouble is related to the fact that frequently ART procedures are associated to antithrombotic treatment with aspirin and lor low molecular weight heparin per se in order to have an increase of successful pregnancy [7,21]. Another frequent extratrouble to evaluate the real incidence of thrombotic complications in women prompt to ART is related to the presence of several pharmacological protocols used to increase and to improve the hormonal habit of treated women [22].

However it is well testified that pharmacological ovarian hyperstimulation stimulates hypercoagulable state [4] and this may lead to thrombosis. Venous thrombosis seems to be more frequent than arterial thrombosis and the number of cases of atypical venous thrombosis is more frequent, in particular for upper limb deep vein thrombosis [23]. Several case reports or short case series are available in the Medline in the last 20 years but case-control studies and clinical trials are not present in the Literature. Recently a cohort study showed a slight increase of VTE in pregnant women by ART compared to the VTE's rate present after a spontaneous pregnancy [24].

Thrombotic complications, in fact, may appear in thrombophilic as in non-thrombophilic women so underlining that the thrombotic event may be associated to a complex gene-enviromental interaction [22]. A previous retrospective analysis by Grandone et al. [23] showed most frequent risk factors that may associated to the occurrence of VTE in women treated for ART, while the potential benefit of thromboprophylaxis seems to be effective also in VTE prevention [25].

Furthermore, actually a pharmacological thromboprophylaxis is not suggested by guidelines or scientific societies in women that perform ART to prevent VTE, but the debate if it is indicated is still open and in particular a point of discussion is about the timing of pharmacological thromboprophylaxis [26]. Besides the hypercoagulable state induced by hormonal used drugs for ART, in fact and the presence of thrombohilia that may make easy thrombotic complications in this clinical setting, women that perform ART seem to have further several aspects to be considered as potential pregnancy and pregnancy related rest [27].

\section{Take Home Messages}

The clinical approach to a woman that experienced repeated ART failure is really complex and a multidisciplinary approach may be helpful in the daily clinical management. If also thrombophilia is considered as a possible cause of repeated ART failure in order to prevent VTE, a thorough anamnesis focused on additional transient or permanent thrombotic risk factors (e.g., type of hormonal drugs, timing of exposition to hormonal treatment and dosages of hormonal treatment, smoking habits, obesity, suggested or prolonged bed rest after ART), should be performed in order to understand if antithrombotic treatment may be helpful. In this case LMWH seems to have more efficacies if compared to aspirin alone toward relevant outcome as to prevent VTE andlor to increase pregnancy rate. These aspects are emerging from a variety of studies performed with different inclusion and exclusion criteria and should be validated by better addressed clinical studies or from data from extended registries.

\section{References}

1. Andersen AN, Gianaroli L, Felberbaum R, de Mouzon J, Nygren KG, et al. (2001) Assisted reproductive technology in Europe, 2001. Results generated from European registers by ESHRE. Hum Reprod 16: 2459-2471.

2. Harlin J, Aanesen A, Csemiczky G, Wramsby H, Fried G (2002) Delivery rates following IVF treatment, using two recombinant FSH preparations for ovarian stimulation. Hum Reprod 17: 304-309.
3. Henriksson P, Westerlund E, Wallén H, Brandt L, Hovatta O, et al. (2013) Incidence of pulmonary and venous thromboembolism in pregnancies after in vitro fertilisation: cross sectional study. BMJ 346: e8632.

4. Rogolino A, Coccia ME, Fedi S, Gori AM, Cellai AP, et al. (2013) Hypercoagulability, high tissue factor and low tissue factor pathway inhibitor levels in severe ovarian hyperstimulation syndrome: possible association with clinical outcome. Blood Coagul Fibrinolysis 14: 277-282.

5. Nygren KG, Andersen AN. European IVF-monitoring programme (EIM) Assisted reproductive technology in Europe, 1998. Results generated from European registers by ESHRE. European Society of Human Reproduction and Embryology. Hum Reprod 2001; 16: 2459-2471.

6. Goswamy RK, Williams G, Steptoe PC (1988) Decreased uterine perfusion-a cause of infertility. Hum Reprod 3: 955-959.

7. Micco PD, D'Uva M, Lodigiani C, Rota LL (2010) Thrombophilia and repeated in vitro fertilisation and embryo transfer failure: an open issue. Thromb Haemost 103: $472-473$.

8. Qublan HS, Eid SS, Ababneh HA, Amarin ZO, Smadi AZ, et al. (2006) Acquired and inherited thrombophilia: implication in recurrent IVF and embryo transfer failure. Hum Reprod 21: 2694-2698.

9. Safdarian L, Najmi Z, Aleyasin A, Aghahosseini M, Rashidi M, et al. (2014) Recurrent IVF failure and hereditary thrombophilia. Iran J Reprod Med 12: 467 470.

10. Simur A, Ozdemir S, Acar H, Colakoglu MC, Gorkemli H, et al. (2009) Repeated in vitro fertilization failure and its relation with thrombophilia. Gynecol Obstet Invest 67:109-112.

11. Martinelli I, Taioli E, Ragni G, Levi-Setti P, Passamonti SM, et al. (2003) Embryo implantation after assisted reproductive procedures and maternal thrombophilia. Haematologica 88: 789-793.

12. Grandone E, Colaizzo D, Bue AL, Checola MG, Cittadini E, et al. (2001) Inherited thrombophilia and in vitro fertilization implantation failure. Fertil Steril 76: 201-202.

13. Nisio MD, Rutjes AW, Ferrante N, Tiboni GM, Cuccurullo F, et al. (2011) Thrombophilia and outcomes of assisted reproduction technologies: a systematic review and meta-analysis. Blood 118: 2670-2678.

14. Qublan H, Amarin Z, Dabbas M, Farraj AE, Beni-Merei Z, et al. (2008) Lowmolecular-weight heparin in the treatment of recurrent IVF-ET failure and thrombophilia: a prospective randomized placebo-controlled trial. Hum Fertil (Camb) 11: 246-253.

15. Stern C, Chamley L, Norris H, Hale L, Baker HW (2003) A randomized, doubleblind, placebo-controlled trial of heparin and aspirin for women with in vitro fertilization implantation failure and antiphospholipid or antinuclear antibodies. Fertil Steril 80: 376-383.

16. Sher G, Zouves C, Feinman M, Maassarani G, Matzner W, et al. (1998) A rational basis for the use of combined heparin/aspirin and IVIG immunotherapy in the treatment of recurrent IVF failure associated with antiphospholipid antibodies. Am J Reprod Immunol 39: 391-394.

17. Berker B, Taskin S, Kahraman K, Taskin EA, Atabekoğlu C, et al. (2011) The role of low-molecular-weight heparin in recurrent implantation failure: a prospective, quasi-randomized, controlled study. Fertil Steril 95: 2499-2502.

18. Noci I, Milanini MN, Ruggiero M, Papini F, Fuzzi B, et al. (2011) Effect of dalteparin sodium administration on IVF outcome in nonthrombophilic young women: a pilot study. Reprod Biomed Online 22: 615-620.

19. Dentali F, Grandone E, Rezoagli E, Ageno W (2011) Efficacy of low molecular weight heparin in patients undergoing in vitro fertilization or intracytoplasmic sperm injection. J Thromb Haemost 9: 2503-2506.

20. Lodigiani C, Dentali F, Banfi E, Ferrazzi P, Librè L, et al. (2017) The effect of parnaparin sodium on in vitro fertilization outcome: a prospective randomized controlled trial. Thromb Res 159: 116-121.

21. Dentali F, Ageno W, Rezoagli E, Rancan E, Squizzato A, et al. (2012) Low-dose aspirin for in vitro fertilization or intracytoplasmic sperm injection: a systematic review and a meta-analysis of the literature. J Thromb Haemost 10: 2075-2085

22. Hansen AT, Kesmodel US, Juul S, Hvas AM (2014) Increased venous thrombosis incidence in pregnancies after in vitro fertilization. Hum Reprod 29: 611-617.

23. Lawrenz B, Beligotti F, Engelmann N, Gates D, Fatemi HM (2016) Impact of 
Citation: Strina I, Alviggi C, Rosa PD, Avino L, Amoroso R, et al. (2018) Venous Thromboembolism (VTE) and Assisted Reproductive Technologies (ART): A Complex Relationship. J Blood Lymph 8: 199. doi:10.4172/2165-7831.1000199

gonadotropin type on progesterone elevation during ovarian stimulation in GnRH antagonist cycles. Hum Reprod 31: 2554-2560.

24. Grandone E, Colaizzo D, Vergura P, Cappucci F, Vecchione G, et al. (2004) Age and homocysteine plasma levels are risk factors for thrombotic complications after ovarian stimulation. Hum Reprod 19: 1796-1799.

25. Villani M, Dentali F, Colaizzo D, Tiscia GL, Vergura P, et al. (2015) Pregnancyrelated venous thrombosis: comparison between spontaneous and ART conception in an Italian color. BMJ Open 5: e008213.

26. Nelson SM, Greer IA (2008) The potential role of heparin in assisted conception Hum Reprod Update 14: 623-645.

27. Barbar S, Noventa F, Rossetto V, Ferrari A, Brandolin B, et al. (2010) A risk assessment model for the identification of hospitalized medical patients at risk for venous thromboembolism: the Padua Prediction Score. J Thromb Haemost 8: $2450-2457$. 